\title{
Source process of the great 1971 Solomon Islands doublet
}

\author{
Susan Y. Schwartz *, Thorne Lay and Larry J. Ruff \\ Department of Geological Sciences, The University of Michigan, Ann Arbor, MI 48109-I063 (U.S.A.)
}

(Received August 25, 1988; revision accepted September 28, 1988)

\begin{abstract}
Schwartz, S.Y., Lay, T. and Ruff, L.J., 1989. Source process of the great 1971 Solomon Islands doublet. Phys. Earth Planet Inter., 56: 294-310.

Large underthrusting earthquakes in the Solomon Islands tend to occur as multiplets, separated by a few hours to several days in time and 30-100 $\mathrm{km}$ in space. The largest sequence, a doublet on July 14, $1971\left(M_{\mathrm{w}}=8.0\right)$ and July 26 , $1971\left(M_{\mathrm{w}}=8.1\right)$, is particularly unusual in that it occured at the junction of two trenches, with the July 14 event in the Solomon Islands Trench preceding the July 26 rupture in the New Britain Trench. The location and large moment release of this doublet as well as an incompatibility of published body wave and surface wave focal mechanisms for the July 14 event, motivated a detailed study of the source process of the 1971 sequence. To satisfy both the surface wave and body wave data, we explored the possibility of a change in the faulting geometry during rupture for the July 14 event. A fault model that changes orientation from a northwest-southeast striking, shallow-dipping plane, similar to the mechanisms of neighboring underthrusting events in the Solomon Islands Trench, to a more north-south striking plane $\sim 70 \mathrm{~s}$ after rupture initiation is consistent with the observed Rayleigh and Love wave amplitude patterns. This change in mechanism is suggested by systematic variations in the mechanisms of smaller earthquakes near the cusp in the Solomon Islands plate. A simultaneous inversion of WWSSN P wave seismograms for the time, location, seismic moment and focal mechanism of individual subevents gives results in agreement with the surface wave model, although the precise change in mechanism is not well resolved. The spatiotemporal distribution of subevents reveals two major pulses of moment release. The first occurred on the initial fault near the epicenter at the origin time of the earthquake. The second occurred on the north-south striking fault, 50-70 km northwest of the epicenter $\sim 70 \mathrm{~s}$ after the origin time. The change in mechanism appears to reflect contortion of the slab near the trench junction. Inversion of WWSSN $P$ wave seismograms for the rupture history of the July 26 event reveals a westerly propagating rupture extending $\sim 60$ $\mathrm{km}$ along the New Britain Trench. For both of the 1971 earthquakes, regions of high moment release are located in the vicinity of the Solomon Islands-New Britain Trench junction. Contortion of the subducting lithosphere as it bends around the arc-arc junction may have enhanced the degree of mechanical coupling between the subducting and overriding plates, concentrating stress in this region, and in turn, promoting efficient triggering across the trench junction.
\end{abstract}

\section{Introduction}

The largest underthrusting earthquakes in the Solomon Islands tend to occur as multiplets separated by a few hours to several days in time and $30-100 \mathrm{~km}$ in space (Fig. 1). This behavior has been attributed to a specific pattern of fault plane

* Present address: Charles F. Richter Seismological Laboratory, University of California, Santa Cruz, CA 95064, U.S.A. heterogeneity consisting of small strong patches (asperities) spaced closely together such that the failure of one patch has an unusually high probably to trigger slip in immediately adjacent patches (Lay and Kanamori, 1980). The largest earthquake doublet in the Solomon Islands occurred on July 14, $1971\left(M_{\mathrm{w}}=8.0\right)$ and July 26, $1971\left(M_{\mathrm{w}}=8.1\right)$. This sequence differs from other large Solomon Islands earthquake pairs in that, rather than taking place along a linear trench segment, it oc-

0031-9201/89/\$03.50 이 1989 Elsevier Science Publishers B.V. 


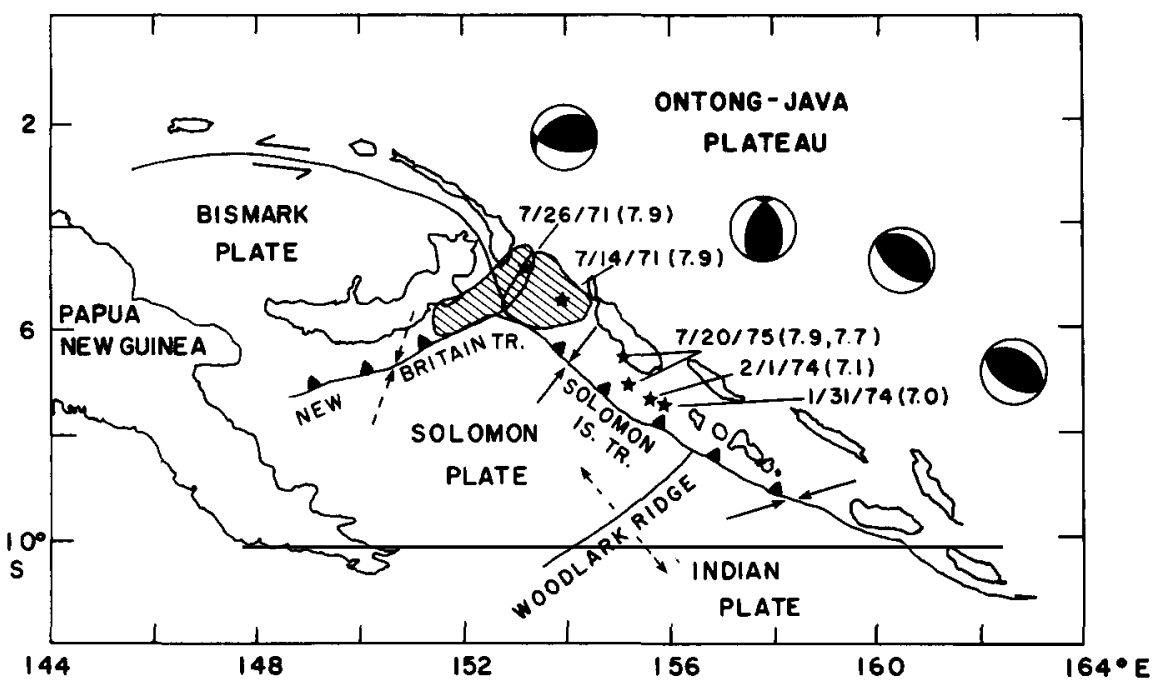

Fig. 1. Map of the Solomon Islands region showing the location of the recent earthquake doublets and relevant tectonic features. The aftershock areas of the largest doublet events on July 14 and July 26 are indicated by the shaded regions. The arrows represent the local relative plate convergence directions. All lower hemisphere focal mechanism solutions are from Lay and Kanamori (1980); the mechanisms shown for the 1974 and 1975 doublet events have been obtained by averaging the values from both doublet events.

curred at the junction of two trenches. The July 14 event is located in the northwestern Solomon Islands Trench, whereas the July 26 event ruptured the northeastern New Britain Trench (Fig. 1). These two earthquakes represent subduction of the Solomon Sea Plate beneath the Pacific Plate and the Bismark Sea Plate respectively (Lay and Kanamori, 1980). This unusual faulting geometry has generated the largest earthquake doublets in the Solomon Islands in this century, including pairs in 1919-1920, 1945-1946, and 1971 (Lay and Kanamori, 1980), suggesting an association between the distribution of stress heterogeneity (asperities) and the contortion of the subducting Solomon Sea Plate.

The asperity model, which attributes the occurrence of the largest earthquakes to the failure of the strongest regions of the fault plane, provides a good conceptual framework for understanding the rupture process of large earthquakes. The model has been successfully invoked to explain many observed earthquake phenomena such as the existence of foreshocks and aftershocks (Kanamori, 1981) and variations of seismic and aseismic slip along plate boundaries (Lay et al., 1982). However, the physical properties of asperities are, as yet, not well known. This paper presents detailed source studies of the July 14 and July 26 Solomon Islands earthquakes in an attempt to provide a better understanding of the physical properties of asperities and of the efficiency of earthquake trig-

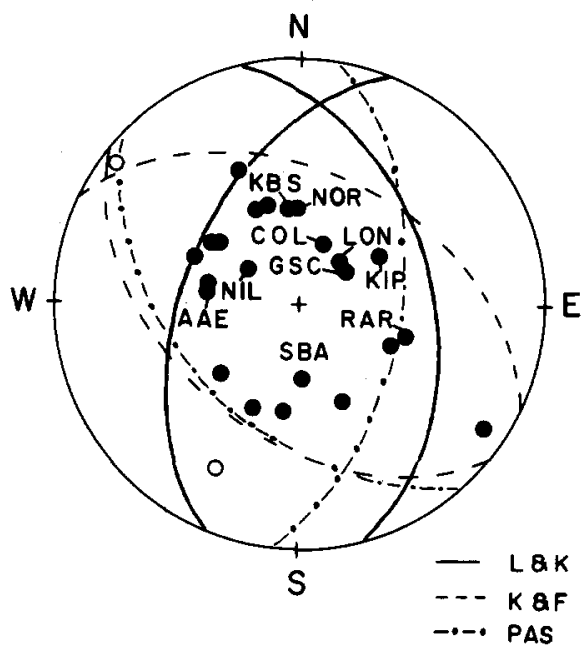

Fig. 2. Lower hemisphere equal area projection of fault plane solutions for the July 14, 1971 earthquake determined from surface waves by Lay and Kanamori (1980), body waves by Kikuchi and Fukao (1987) and from first motions by Pascal (1979). Open and closed circles represent dilatational and compressional first motions picked by the authors, labelled circles are stations used in our body wave inversions. 
gering in the presence of geometric complications in the subducting plate.

\section{July 14, 1971 earthquake}

\subsection{Focal mechanism}

The July 14, 1971 Solomon Islands earthquake occurred at the northwesternmost end of the Solomon Islands Trench. The epicenter $\left(5.5^{\circ} \mathrm{S}\right.$, $153.9^{\circ} \mathrm{E}, \mathrm{ISC}$ ) is located in the southeast quadrant of a quasi-circular aftershock area (Fig. 1). Lay and Kanamori (1980) determined a focal mechanism (strike, $\phi=345^{\circ}, \operatorname{dip}, \delta=45^{\circ}$, rake, $\lambda=$ $62^{\circ}$ ) and a corresponding static seismic moment $\left(M_{0}=12 \times 10^{27} \mathrm{dyn} \mathrm{cm}\right.$ ) for this event by analysis of Rayleigh and Love wave amplitudes. Their mechanism (solid lines in Fig. 2) differs substantially from the solutions they obtained for the 1974 and 1975 doublet events located just to the southeast (Fig. 1).

The 1974 and 1975 earthquakes have shallow dipping, northwest-southeast striking thrust fault planes, which are consistent with an interpretation of underthrusting of the Solomon Sea Plate beneath the Pacific Plate. From an analysis of many earthquake $P$ wave first-motion focal mechanisms, Johnson and Molner (1972) estimated the local relative plate motion between the Solomon Sea Plate and the Pacific Plate to be in the direction $\mathrm{N} 34^{\circ} \mathrm{E}$ (Fig. 1). The convergence direction indicated by the 1974 and 1975 doublet event mechanisms is $\mathrm{N} 35^{\circ} \mathrm{E}$, in close agreement with the local relative plate motion estimate. However, the convergence direction indicated by the surface wave mechanism of Lay and Kanamori (1980) for the July 14 event is $\mathrm{N} 110^{\circ} \mathrm{E}$, much more easterly than the local relative plate motion vector. This raises the question of how accurate the surface wave mechanism is, and whether or not the July 14 event is actually an interplate thrust event.

The July 14 surface wave mechanism is certainly the least well-constrained of the six events studied by Lay and Kanamori (1980), as will be discussed below. We also find that there is an inconsistency between the surface wave mechanism and the first-motion mechanism determined by Pascal (1979) as well as the body wave mechanism published by Kikuchi and Fukao (1987) (Fig. 2). Furthermore, several $P$ wave first motions collected in this study (Fig. 2) are clearly violated by the surface wave mechanism. Kikuchi and Fukao (1987) studied the long-period $P$ waves from this event, and interpreted the source process as a simple unilateral rupture propagating to the northwest along the strike of their preferred fault plane. However, their analysis was somewhat incomplete, as they failed to reconcile their model with the surface wave results of Lay and Kanamori (1980). The inconsistency of the surface wave and body wave analyses, and the apparent incompatibility of the surface wave solution with the local relative plate convergence direction suggest that the July 14 event changed faulting geometry during its rupture process. In this section, we will construct a model for the source process of this earthquake that is consistent with the body wave and long-period surface wave observations as well as with the tectonic framework in which this earthquake occurred. First, we constrain possible faulting geometries using the long-period surface wave observations. Then we examine long-period $P$ wave observations to ensure their compatibility with our preferred model.

\subsection{Surface wave observations}

Lay and Kanamori (1980) analyzed the surface waves from all six earthquakes comprising the 1971, 1974, and 1975 Solomon Islands doublets. They obtained radiation patterns for these events by equalizing all traces to a common propagation distance, filtering the signals using a Gaussian bandpass filter with a short-period cut-off at $40 \mathrm{~s}$, and adjusting the amplitudes to a standard WWSSN (15-100) instrument with a gain of 1500 . Rayleigh wave amplitudes with a period near 220 $s$ and peak-to-peak Love wave amplitudes with a period near $150 \mathrm{~s}$ were used to constrain the mechanisms. Of the six events, the scatter in the observed radiation patterns is most severe for the July 14, 1971 event. The corresponding measurements are shown in Fig. 3, with it being apparent that a simple double couple radiation will not match the data well. The observed surface wave 


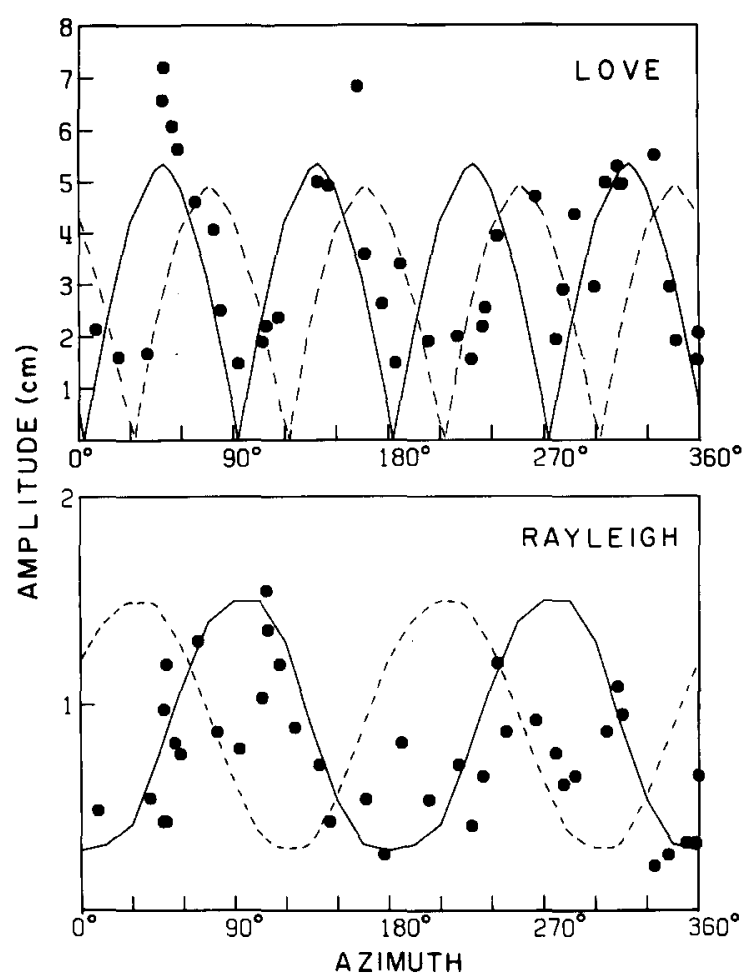

Fig. 3. Equalized trace amplitudes for observed $G_{3}$ and $R_{3}$ data as a function of azimuth for the July 14, 1971 event. The solid and dashed curves represent the radiation patterns predicted by the surface wave mechanism of Lay and Kanamori (1980) and the body wave mechanism of Kikuchi and Fukao (1987) respectively.

radiation patterns of the larger of the 1971 Solomon Islands doublet pair (July 26), show significantly less scatter (Lay and Kanamori, 1980), indicating that the variation in amplitudes of the nearby July 14 event cannot be explained by propagation effects alone. This suggests a significant component of source complexity. The Rayleigh and Love wave radiation patterns predicted by the mechanism of Kikuchi and Fukao (1987) are respectively 60 and $30^{\circ}$ out of phase with the Rayleigh and Love wave radiation patterns predicted by Lay and Kanamori's (1980) surface wave mechanism, and certainly provide an inferior fit to the observed amplitudes (Fig. 3) despite the data variability.

As the focal mechanism of Kikuchi and Fukao (1987) is consistent with our first-motion observations as well as with the local plate convergence direction, we sought a model which starts with this mechanism and then changes to a second orientation such that moment-weighted and time-lagged superpositions of both Rayleigh and Love waves for the composite source match the observed surface wave radiation patterns. As an additional constraint, we restricted the second mechanism to be as consistent as possible with the local plate convergence direction. This is motivated by our belief that this event represents interplate thrusting only, rather than containing a component of intraplate deformation. The along-trench distribution of the aftershocks supports this contention.

Given that the analog surface wave data are rather noisy, and phase information is not available, we could not perform a formal inversion for the change in mechanism. To provide guidance in our construction of a reasonable composite fault model, we examined the mechanisms of smaller events in the region. Earthquake centroid moment tensor solutions determined by Harvard for all events with magnitudes $>5.0$ since 1977 were first used to recompute the local convergence direction between the Solomon Sea Plate and the Pacific Plate. We determined the plate convergence direction from the major double couple orientation obtained from the averaged values of the moment tensor elements for the 90 underthrusting earthquakes occurring between 3.5 and $9.0^{\circ} \mathrm{S}$ and 152 and $157^{\circ} \mathrm{E}$. Our average convergence direction of $\mathrm{N} 46^{\circ} \mathrm{E}$ is $11^{\circ}$ more easterly than the direction determined by Johnson and Molnar (1972); however, given the large number of well-determined focal mechanism solutions incorporated in this analysis, we feel that our value is more representative of the average local convergence direction.

To ascertain whether there is a systematic change in the orientation of focal mechanisms along the strike of the Solomon Islands Trench, we computed the average major double couple orientation for four different latitude-longitude bands. These values reveal a tendency for the northeasterly dipping nodal plane to rotate from a west-northwest-east-southeast striking orientation $\left(308^{\circ}\right)$, to a more north-south orientation $\left(331^{\circ}\right)$ as the junction with the New Britain Trench is approached. In fact, many focal mechanism solu- 


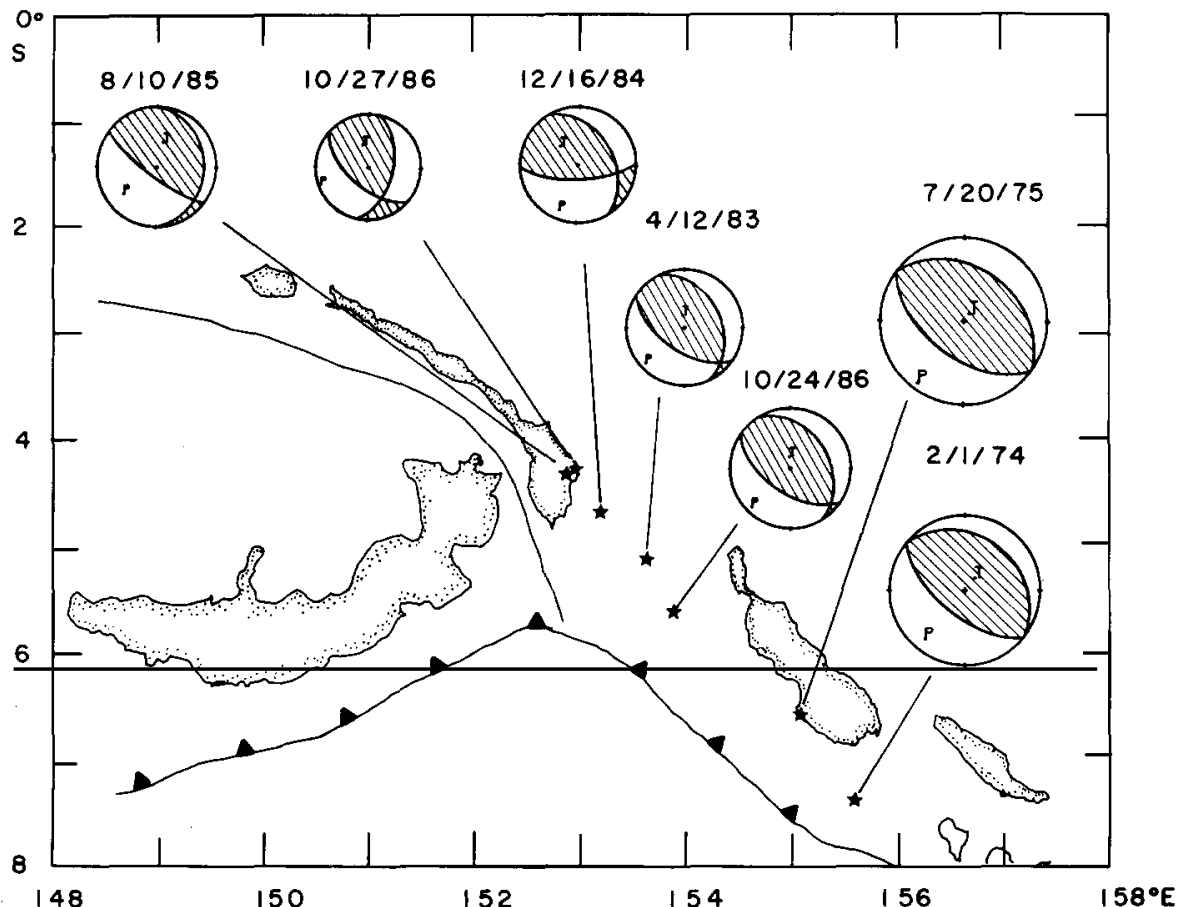

Fig. 4. Focal mechanism solutions of some recent underthrusting earthquakes in the northern Solomon Islands Arc. The size of the mechanism is proportional to the earthquake magnitude. Shaded quadrants represent compressional first motions. These mechanisms suggest a northward rotation of the fault plane as the junction with the New Britain Trench is approached.

tions for earthquakes in the vicinity of the Solomon Islands-New Britain Trench junction have shallow-dipping nodal planes that strike due north-south or north-northeast-south-southwest. Several solutions obtained for recent thrust earthquakes in the northern Solomon Islands Trench are shown in Fig. 4. The focal mechanism solutions for the 1974 and 1975 events were determined by surface wave analysis (Lay and Kanamori, 1980), whereas the other mechanisms are Harvard centroid moment tensor solutions as listed in the National Earthquake Information Center (NEIC) Preliminary Determination of Epicenters. Assuming that these earthquakes are interplate events, the rotation of the shallowly dipping nodal plane suggests that the thrust contact curves to the north in the vicinity of the Solomon Islands-New Britain Trench junction.

With these observations in mind, we modeled the observed surface wave radiation patterns by constraining the initial radiation to be consistent with the body wave solution of Kikuchi and Fukao
(1987) and assuming various second focal mechanisms similar to those of the August 10, 1985 and October 27, 1986 Solomon Islands earthquakes (Fig. 4). Synthetic Rayleigh and Love waves were computed for the two mechanisms, with the relative weights and temporal lags determined by trial and error as those values which gave the best fit to the observed radiation patterns as measured by a least squares variance reduction. The synthetic seismograms were computed using the technique of Kanamori (1970) for point sources located at the epicenter at a depth of $33 \mathrm{~km}$. The resulting composite amplitude patterns are quite sensitive to the temporal lag between the two sources; however, the effect of any spatial separation of the subevents, for distances $<200 \mathrm{~km}$, is negligible and we did not include it in computing our synthetics. Our best match, although a non-unique one, to the observed Rayleigh and Love wave amplitude patterns was obtained for a faulting model that changes orientation from $\phi=295^{\circ}$, $\delta=45^{\circ}, \lambda=80^{\circ}$, to $\phi=20^{\circ}, \delta=30^{\circ}, \lambda=130^{\circ}$, 


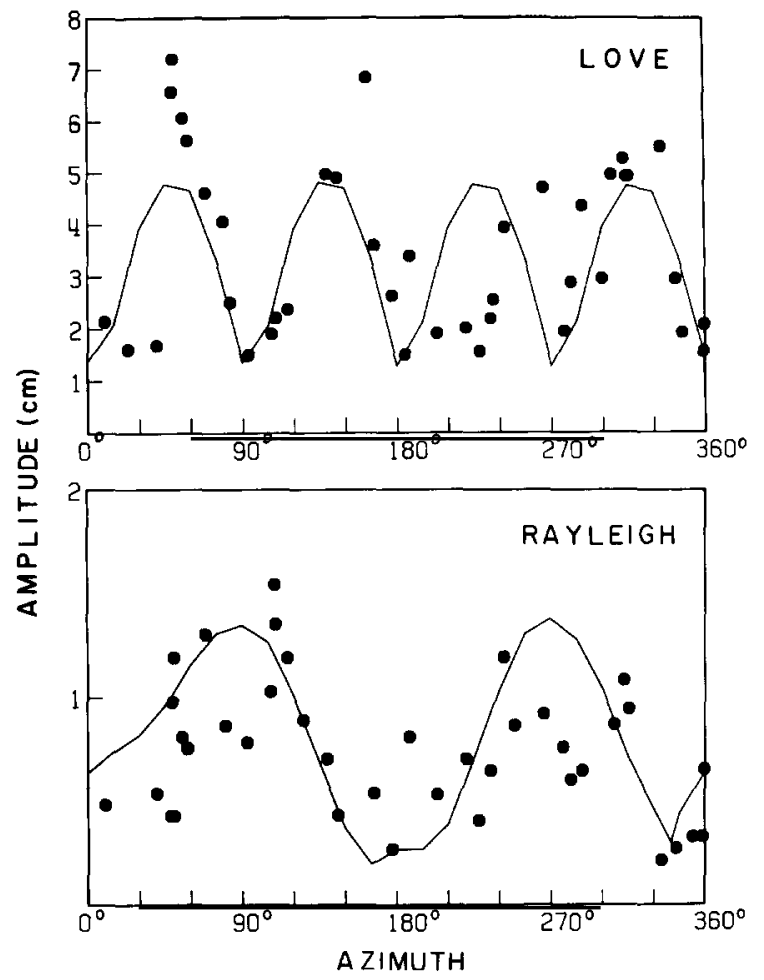

Fig. 5. Equalized trace amplitudes for observed $G_{3}$ and $R_{3}$ data as a function of azimuth for the July 14, 1971 event. The solid curves represent the radiation pattern resulting from a weighted and time lagged sum of Love and Rayleigh waves computed for a mechanism with $\phi=20^{\circ}, \delta=30^{\circ}$ and $\lambda=$ $130^{\circ}$ and for Kikuchi and Fukao's (1987) body wave mechanism $\left(\phi=295^{\circ}, \delta=45^{\circ}, \lambda=80^{\circ}\right)$.

$\sim 70 \mathrm{~s}$ after rupture initiation (Fig. 5). This composite faulting geometry yields a total seismic moment of $16 \times 10^{27} \mathrm{dyn} \mathrm{cm}$, with $4 \times 10^{27}$ and $12 \times 10^{27} \mathrm{dyn} \mathrm{cm}$ partitioned into the first and second mechanisms respectively. The interplate convergence direction indicated by the second mechanism is $\mathrm{N} 66^{\circ} \mathrm{E}$, which is $20^{\circ}$ more easterly than our redetermined direction of $N 46^{\circ} \mathrm{E}$, but is much more consistent with the local plate convergence direction than the surface wave solution obtained by Lay and Kanamori (1980). However, we cannot totally eliminate the possibility that the second mechanism represents internal deformation of the subducted slab and is therefore independent of the local convergence direction.

The considerable scatter in the observed surface wave amplitudes is impossible to fit well with any simple composite faulting geometry. This scatter is all the more significant given the simple double couple radiation pattern for the other large Solomon Islands events (Lay and Kanamori, 1980). Through forward modeling, we have tried to find an acceptable solution that is compatible with both the first-motion and surface wave data, as well as with the local tectonic setting indicated by the regional earthquake focal mechanisms. Our solution, although highly non-unique, is tectonically reasonable and suggests that the July 14, 1971 event began along a northwest-southeast striking fault plane which rotates toward the north as it approaches the junction with the New Britain Trench. Given the limitations of the data we did not explore more complex parameterizations of the source. Next, we examine the long-period $P$ waves to test whether or not they corroborate the faulting model we obtained from the surface waves.

\section{3. $P$ wave modeling}

Our data consist of long-period vertical and horizontal component World Wide Standardized Seismograph Network) P and PP wave seismograms. Horizontal component $P$ wave seismograms were used when the vertical components were off-scale, with the receiver factors being determined by comparing the corresponding horizontal and vertical component wave amplitudes for the first few $P$ wave cycles. Because of the large magnitude and remote location of the July 14, 1971 event relative to many WWSSN stations, on-scale undiffracted $P$ waves are scarce. To supplement the $\mathbf{P}$ wave data set and to improve the azimuthal distribution of stations relative to the source, PP phases in the distance region $90-123^{\circ}$ were also modelled. These phases were Hilbert transformed to remove the effects of the caustic and free surface reflection (Lynnes and Ruff, 1985). In all, we obtained seven undiffracted $P$ wave seismograms and three PP wave seismograms for this event. Four of the $P$ wave seismograms were from horizontal components (LON, KIP, SBA, and NIL).

An iterative multi-station deconvolution technique for the time, location and seismic moment of individual subevents, developed by Kikuchi and 
Kanamori (1982, 1986), was used to determine the spatiotemporal variation in moment release for the July 14, 1971 event. The body waves for this event are characterized by two main displacement pulses (see Fig. 9) in the first $120 \mathrm{~s}$ of rupture. To assess the best starting mechanism and depth of rupture initiation, the inversion was first conducting using a short (50 s) time window which included only the first of the two body wave pulses. This inversion was performed with all subevents having the same faulting geometry, a constraint that will be relaxed later to test the hypothesis of a change in focal mechanism during the rupture process.

The parameters assumed in the construction of all Green's functions were $P$ wave velocities $v_{\mathrm{p}}=$ 6.0 and $6.8 \mathrm{~km} \mathrm{~s}^{-1}$ for the surface and the source respectively ( $\mathrm{S}$ wave velocity is $v_{\mathrm{p}} / 1.732$ ), source density of $3.3 \mathrm{~g} \mathrm{~cm}^{-3}$, water depth of $4 \mathrm{~km}, t^{*}$ of $1.0 \mathrm{~s}$ and $2.0 \mathrm{~s}$ for $\mathrm{P}$ and PP phases respectively and geometric spreading factors appropriate for a Jeffreys-Bullen Earth model.

Ten iterations of the inversion procedure were performed using the first $50 \mathrm{~s}$ of all 10 traces for point sources, varying in depth at $5-10-\mathrm{km}$ increments. The residual waveform misfit vs. depth curves for three different choices of focal mechanisms are shown in Fig. 6. The smallest waveform residuals are obtained for depths between 20 and $30 \mathrm{~km}$ for the three assumed mechanisms. The focal mechanism of Kikuchi and Fukao (1987), which we used as our initial mechanism in the surface wave modeling, yielded the best error reduction for this inversion of the first $50 \mathrm{~s}$. This provides additional support for our assumption that the initial stage of rupture had this orientation.

We next explored the possibility of a change in the faulting geometry by performing finite fault inversions using a $150 \mathrm{~s}$ time window, which spans the entire $P$ wave radiation. The second major pulse of $P$ wave energy occurs $\sim 70 \mathrm{~s}$ into the waveforms, and exhibits an azimuthal variation relative to the first pulse that is suggestive of a change in focal mechanism. Synthetic wavelets were computed for both the initial mechanism ( $\phi=295^{\circ}, \delta=45^{\circ}, \lambda=80^{\circ}$ ) and for the second mechanism suggested by our surface wave analysis

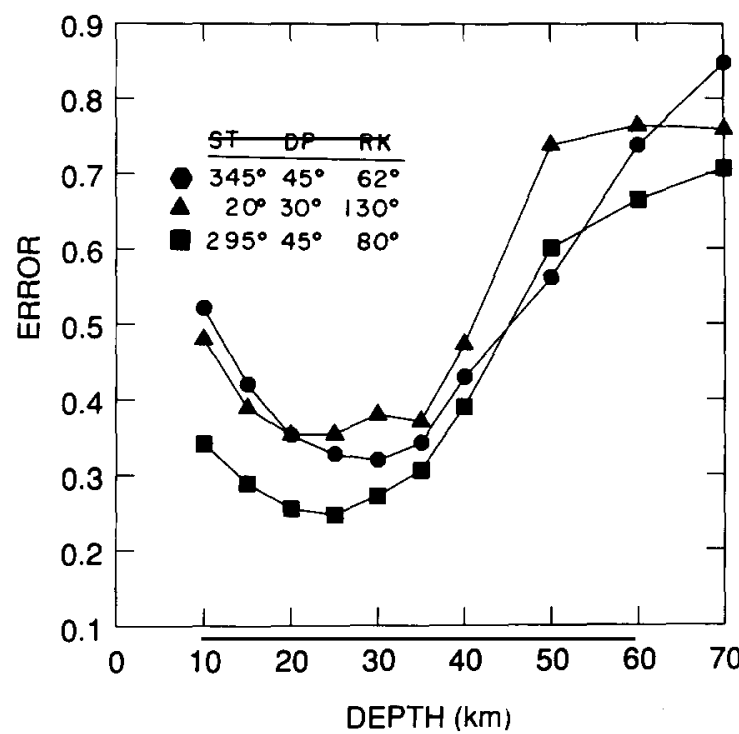

Fig. 6. Plot of residual waveform misfit (error) vs. depth after 10 iterations of the simultaneous deconvolution of body waves for the July 14, 1971 event. The three different curves are for three different focal mechanisms. The best waveform fit is obtained for depths between 20 and $30 \mathrm{~km}$ for all three focal mechanisms.

$\left(\phi=20^{\circ}, \delta=30^{\circ}, \lambda=130^{\circ}\right.$ ) for 11 point sources distributed along the trench at $20 \mathrm{~km}$ intervals with depths of $25 \mathrm{~km}$ and symmetric trapezoidal time functions ( $3 \mathrm{~s}$ time, $8 \mathrm{~s}$ total duration). The time, location, choice between each focal mechanism at a given location and time, and moment of each subevent were determined as those values that maximized the correlation of the synthetic wavelet with the observed records, following Kikuchi and Kanamori (1986). We then used the location of the subevents with the second mechanism to reinvert the data assumming a composite faulting geometry. The final segmented fault parameterization that we adopted consisted of 16 point sources distributed along the trench at 10 $\mathrm{km}$ increments. The first nine sources $(90 \mathrm{~km})$ followed the strike of the first mechanism, while the next seven sources followed the strike of the second mechanism. The first nine and next seven fault elements were constrained to use the prescribed first and second mechanisms respectively in computing their associated source wavelets for each station. The source wavelets were constructed 
with the same depth and trapezoidal time function used in the previous inversion.

Contour plots of the correlation of the synthetic wavelets with the observed records as a function of time from the origin time and distance from the epicenter $(\Gamma(t, l))$ for the segmented faulting geometry are shown for the first two inversion iterations in Fig. 7. The parallel shaded bands in the correlation function indicate that the temporal resolution of subevents is much better than the spatial resolution. The stairstep nature of the contour plot borders is the result of applying a constraint of $4 \mathrm{~km} \mathrm{~s}^{-1}$ on the maximum rupture velocity. At the beginning of the iteration procedure (Fig. 7a), a peak in the correlation function is marked with an $\times$ at $t=4 \mathrm{~s}, l=10 \mathrm{~km}$ in a direction to the southeast from the epicenter along the strike on the first fault. Although the $x$ indicates the spatial location of the maximum value in the correlation coefficient, the contour plot indicates that values nearly as high also exist at the epicenter and $10 \mathrm{~km}$ northwest along the strike of the first fault plane. After the first iteration, in which the corresponding wavelet is removed from the data, a peak in $\Gamma(t, l)$ is found at $t=69 \mathrm{~s}, l=50 \mathrm{~km}$. Values of the correlation coefficient nearly as high also occur at the same time for distances of 60 and $70 \mathrm{~km}$ from the epicenter. This second subevent takes place on the second fault. A pulse at the same time using the radiation pattern of the first event would match some of the data, but the variance reduction is not as large as using the second mechanism. This slightly favors a change in mechanism; however, the optimal secondary orientation is difficult to determine formally with this procedure.

The moment rate function and the spatial and temporal locations of the subevent point sources obtained after 15 iterations are shown in Fig. 8. The spatiotemporal plot of subevents (Fig. 8), reveals four major subevents constituting two distinct pulses of moment release. The earliest three subevents occur on the first fault, with an initial pulse at the epicenter and origin time of the earthquake, and the next two pulses $\sim 10$ and 30 $\mathrm{km}$ southeast of the epicenter within the first $10 \mathrm{~s}$ after rupture initiation. Together, these comprise the initial pulse of moment release, for which we
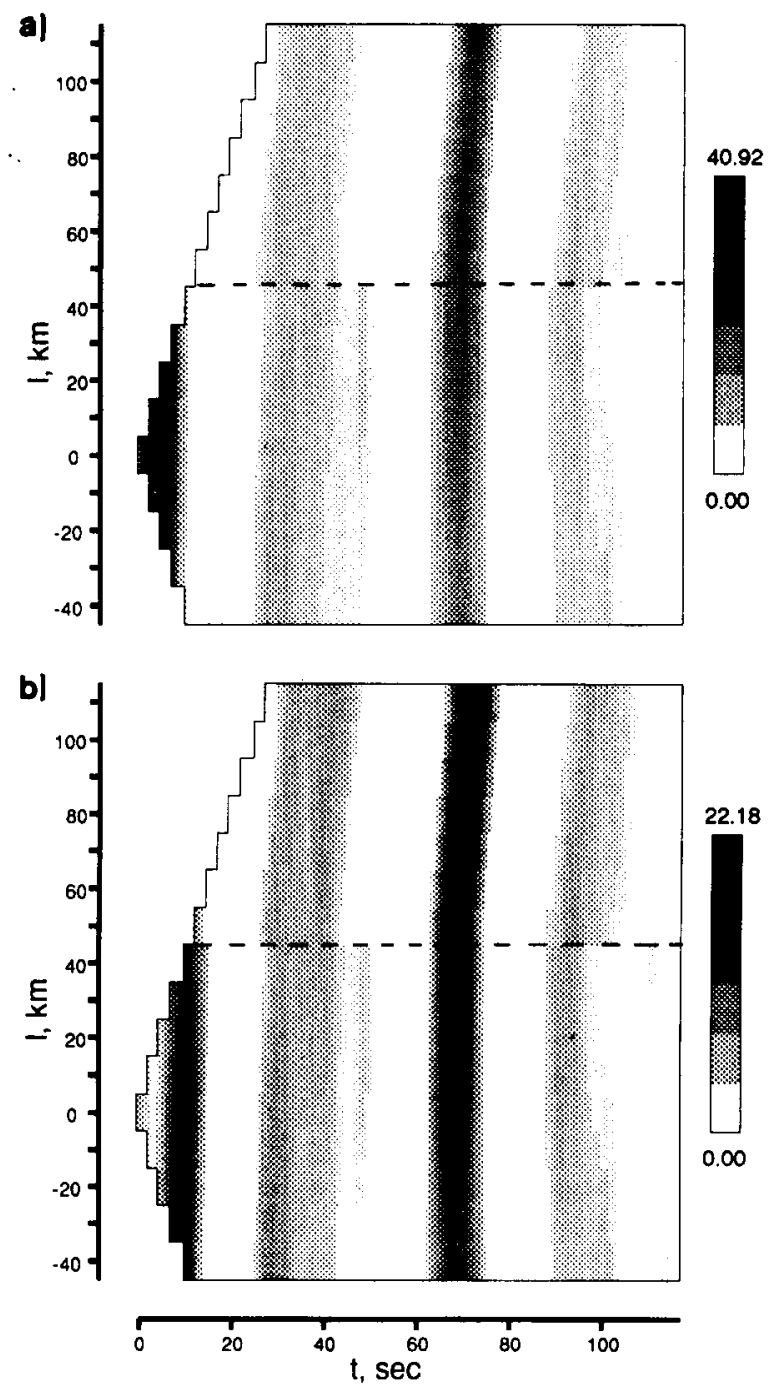

Fig. 7. Contour plots of the correlation between synthetic source wavelets and the observed records as a function of time from the origin time and distance from the epicenter $(0 \mathrm{~km})$ of the July 14, 1971 event. Plots are shown for the first two iterations of the inversion procedure. Source wavelets were constructed using two different focal mechanisms, the first 9 sources (below dashed line) and the next 7 sources (above dashed line) were constrained to use the following two mechanisms respectively: $\phi=295^{\circ}, \delta=45^{\circ}, \lambda=80^{\circ}$ and $\phi=20^{\circ}$, $\delta=30^{\circ}$ and $\lambda=130^{\circ}$. (a) At the first iteration, a peak value of the correlation function is marked with an $x$ at $t=4 \mathrm{~s}$, $l=-10 \mathrm{~km}$. (b) At the second iteration a peak value is identified at $t=69 \mathrm{~s} l=50 \mathrm{~km}$.

cannot reliably resolve a direction of rupture propagation. The south subevent occurs on the second fault $50 \mathrm{~km}$ to the northwest of the epi- 
(A)
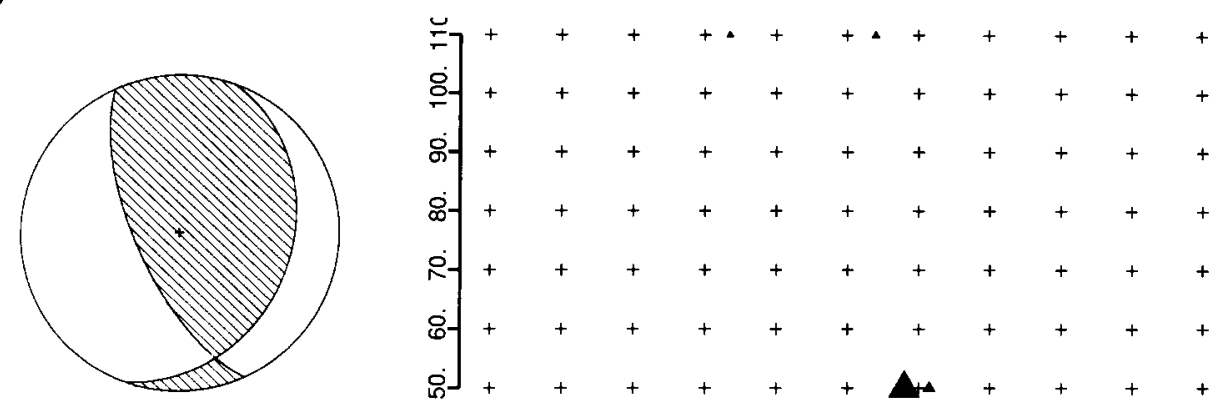

(B)
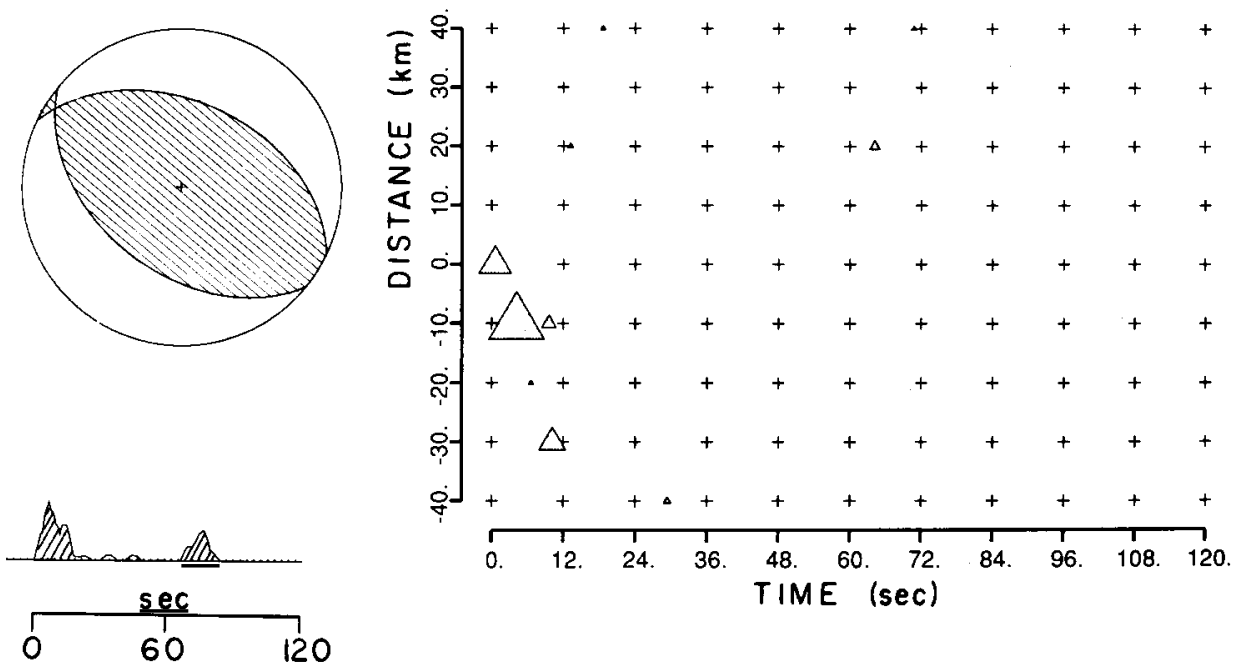

Fig. 8. (A) Spatiotemporal plot of subevents after 15 iterations of the composite fault model inversion for the July 14 event. Lower hemisphere equal area projections of the two focal mechanisms assumed in the inversion are shown beside their relevant fault segments. A major episode of moment release is associated with each fault segment. (B) Average source time function obtained from the body wave inversion. The two pulses of moment rate correspond to subevents occurring on the first and second fault segments.

center at a time of $69 \mathrm{~s}$. The corresponding observed and synthetic seismograms and individual station source spike trains are shown in Fig. 9. The reduction in the error after 15 iterations is 66\%.

We performed the segmented fault inversion several times for different assumptions of the strike, dip, and rake of the second mechanism. In general, the body waves are relatively insensitive to the orientation of the second mechanism. The spatiotemporal locations of subevents, as well as the total error reduction, are similar for a variety of underthrusting mechanisms. This lack of resolution was confirmed by applying the waveform inversion procedure of Nabelek (1984), which explicitly inverts for the fault orientation.

Although the $P$ waves are not very sensitive to the spatial location of the later subevents or to the associated focal mechanism (Fig. 7), they do provide good resolution of timing. The timing of the second largest subevent (69 s), which occurs on the second fault, is consistent with our preferred estimate for the temporal lag between the same two mechanisms as indicated by the surface waves. The moment rate function deconvolved from the body waves (Fig. 8B) indicates that the second event contains only half as much moment as the first. To match the observed surface wave ampli- 
JULY 14,1971

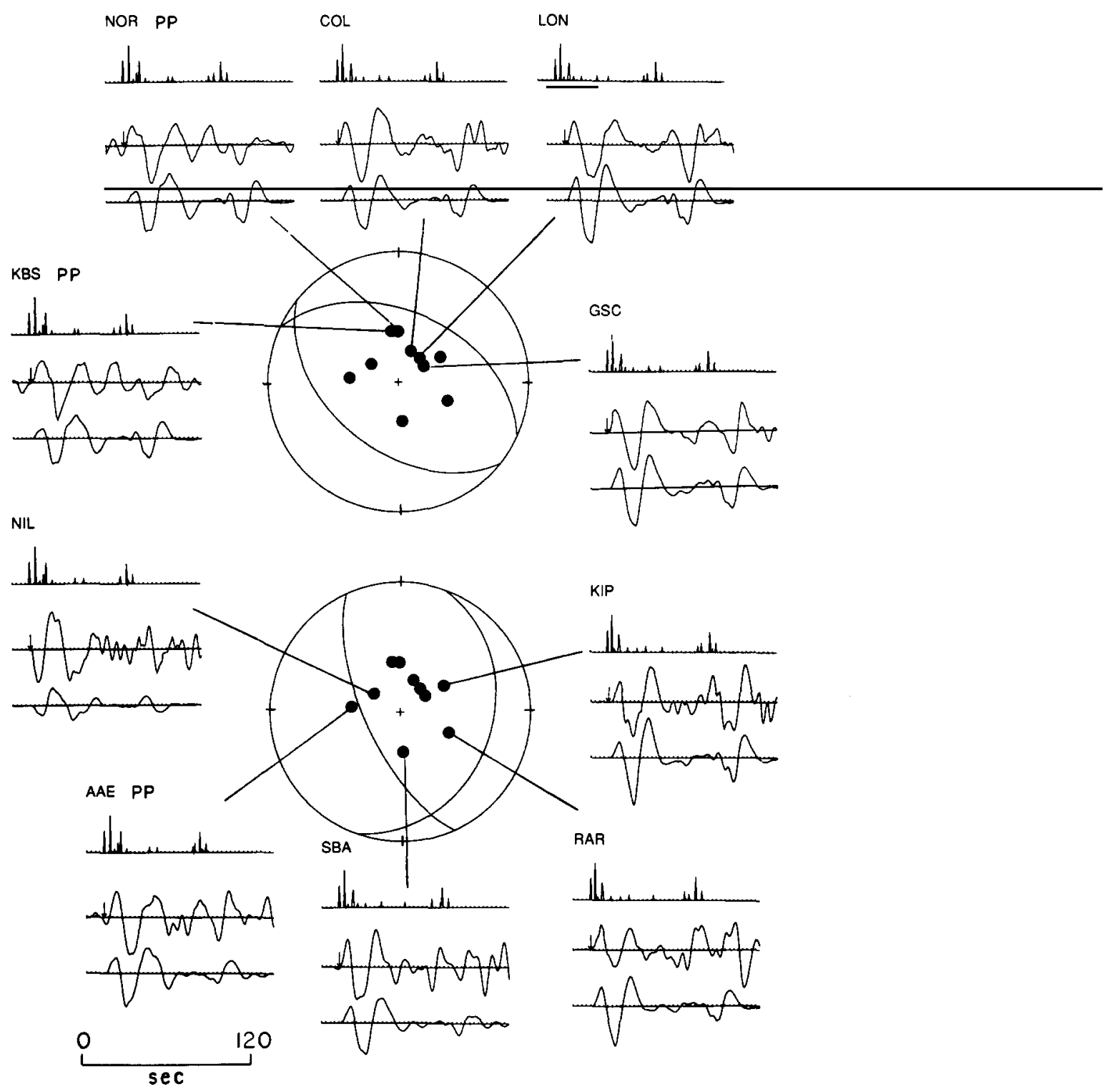

Fig. 9. Observed (top) and synthetic (bottom) seismograms and deconvolved spike trains from individual stations resulting from the multi-station inversion. The station locations are shown on lower hemisphere equal area projections fo the two focal mechanisms used in the inversion. Closed circles represent compression first motions.

tudes, we found that the second event had to be given three times more moment than the first event. This difference in the partitioning of moment release for surface and body waves is not unexpected, considering that the body wave mo- ment obtained by the inversion is $3.0 \times 10^{27} \mathrm{dyn}$ $\mathrm{cm}$-only a small fraction of the value obtained from the surface wave modeling. Therefore it appears that the long-period component of the moment rate function is dominated by the geometry 
of the second mechanism, whereas the limited bandwidth of the body waves precludes retrieval of the actual total moment.

To summarize the results for the July 14 event, we find that the higher-frequency characteristics of the rupture process, as revealed by the body waves, indicate two main episodes of moment release (Fig. 8B). Most of the moment in this frequency band was released close to the epicenter in the first impulsive episode, as suggested by Lay and Kanamori (1980). Although the spatial location and focal mechanism of the second event are not well resolved, consideration of both the body wave and surface wave data suggests that a change in the faulting geometry may be appropriate $50-70$ $\mathrm{km}$ northwest of the epicenter. We interpret this change in the faulting geometry as reflecting the northward curvature of the fault plane as it approaches the junction with the New Britain Trench. Our idealized modeling of this complexity with only two double couple mechanisms reflects our data limitations, and we do not intend the specific model parameters to be overinterpreted. The two episodes of impulsive moment release, apparent in the body waves, may indicate the rupture of asperities (strong patches) on the fault plane. These asperities are located near the epicenter and adjacent to the Solomon Islands-New Britain arc-arc junction. We will return to this interpretation later, after examining the rupture process of the second 1971 Solomon Islands doublet partner.

\section{July 26, 1971 earthquake}

The July 26, 1971 Solomon Islands earthquake occurred at the northeastern end of a northeast-southwest elongate aftershock area (ISC location: $4.9^{\circ} \mathrm{S}, 153.2^{\circ} \mathrm{E}$ ), only $100 \mathrm{~km}$ northwest of the July 14,1971 epicenter. The surface wave focal mechanism $\left(\phi=240^{\circ}, \delta=40^{\circ}, \lambda=55^{\circ}\right)$ determined by Lay and Kanamori (1980) is consistent with the interpretation of oblique underthrusting of the Solomon Sea Plate beneath the New Britain Trench (Fig. 1) as well as with $P$ wave first motions. Lay and Kanamori (1980) estimated the seismic moment, rupture length, rupture direction and rupture velocity by mod- eling asymmetries observed in the long-period Rayleigh and Love wave amplitude patterns. They found that a bilateral rupture of $200 \mathrm{~km}$ to the southwest and $100 \mathrm{~km}$ to the northeast at a velocity of $2.5 \mathrm{~km} \mathrm{~s}^{-1}$ could match the observed amplitude radiation patterns for a moment of $18 \times$ $10^{27}$ dyn $\mathrm{cm}$.

We studied the long-period $P$ waves from the July 26, 1971 event to characterize the rupture process in more detail. We have obtained the spatiotemporal variations in the moment release by applying both single station and multi-station deconvolution techniques. Our data set consists of $8 \mathrm{P}$ and $2 \mathrm{PP}$ phases; four of the $\mathrm{P}$ waves are horizontal components (COL, COR, SBA, and $\mathrm{KOD}$ ), and receiver factors were computed in the same manner as for the July 14 event. Unfortunately, all of the vertical component $P$ waves are diffracted around the outer core, resulting in diminished amplitudes for which geometric spreading corrections are not known. Therefore, in contrast to the analysis of the July 14 event, when performing the multi-station deconvolution the amplitudes of the $P$ waves from the July 26 event have been scaled to give equal moment estimates. All Green's function parameters, with the exception of the focal mechanism and depth, are the same as those used for the July 14 event.

\subsection{Single station deconvolutions}

The $P$ and PP phases from all 10 stations were deconvolved using the technique of Ruff and Kanamori (1983), assuming a source Green's function uniformly distributed from 15 to $55 \mathrm{~km}$ and the focal mechanism of Lay and Kanamori (1980). The resulting source time functions computed at 2 $s$ intervals and the observed and synthetic seismograms are shown in Fig. 10. The source time functions consist of a single pulse of moment release which exhibits clear directivity; stations to the west indicate a shorter duration than stations at other azimuths. A graphical display of this directivity is shown in Fig. 11, where the times of the truncations of the moment rate functions (marked with arrows in Fig. 10) are plotted against the directivity parameter. The best rupture azimuth is determined as that azimuth which yields the 

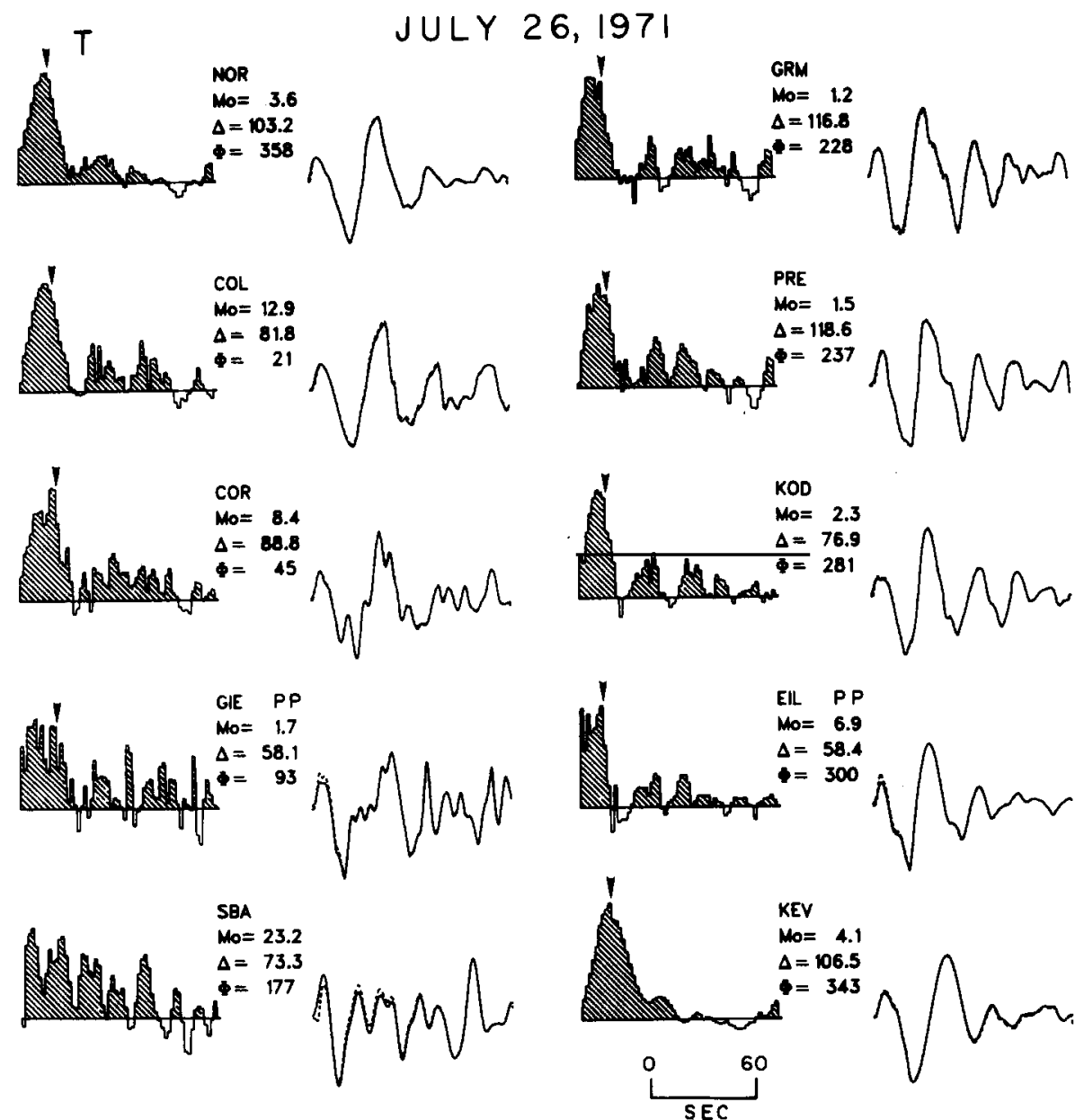

Fig. 10. Single station deconvolved source time functions for the July 26, 1971 Solomon Islands earthquake together with the observed (solid trace) and synthetic (dashed trace) seismograms. Distances $(\Delta)$ and azimuths $(\Phi)$ are in degrees and moments ( $M_{0}$ are in units of $10^{27} \mathrm{dyn} \mathrm{cm}$. Arrows mark the location of the feature used in the directivity study (T); station SBA was excluded from the directivity study.

best-fit line through the data; the largest correlation coefficient between the delay time and directivity parameter was obtained for an azimuth of $270^{\circ}$ (Fig. 11). The distance and delay time of the truncation event are given by the slope and $y$ intercept of the best-fit line through the data; these values are $66 \pm 9 \mathrm{~km}$ and $18.7 \pm 0.3 \mathrm{~s}$ respectively. Station SBA was excluded from the directivity analysis as its moment rate function is more complex than the others and it was difficult to choose a truncation time. Values of the seismic moment obtained from the undiffracted $P$ waves are scattered (Fig. 10), and in general are less than half of the value obtained from the long-period surface waves.

\subsection{Multi-station deconvolutions}

To examine further the spatial characteristics of the rupture process, the iterative multi-station deconvolution technique of Kikuchi and Fukao (1985) was applied to the $P$ and PP waveforms of the July 26 event. This technique includes the possibility of a vertical component to the rupture by specifying point source locations along a twodimensional grid. We used a $9 \times 4$ grid with a 


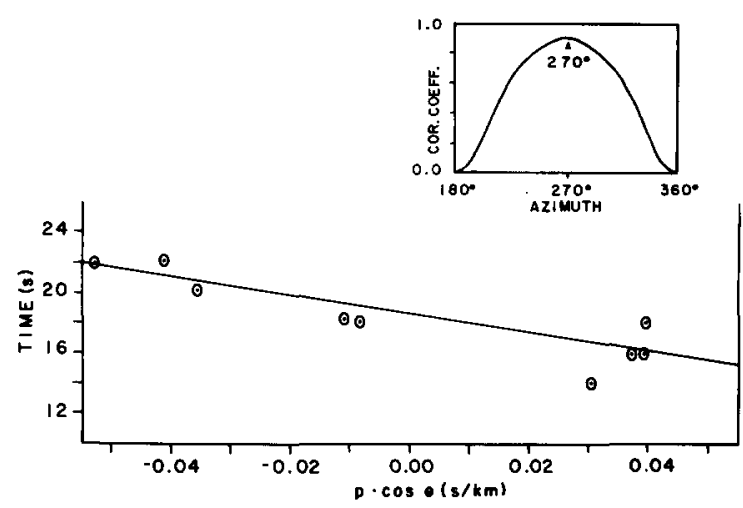

Fig. 11. Directivity observed for the truncation of the moment rate functions $(T)$ for the July 26 event (Fig. 10). The slope of the best fit line $(66 \mathrm{~km})$ is the distance to this feature and the $y$ intercept $(18.7 \mathrm{~s})$ is the delay time. The inset shows the correlation coefficient as a function of assumed rupture azimuth. An azimuth of $270^{\circ}$ yields the largest correlation coefficient.

total length of $180 \mathrm{~km}$ and depths at $15,28,41$, and $54 \mathrm{~km}$. All of the point sources have the focal mechanism of Lay and Kanamori (1980) and the same time history. Other model parameters were the same as used for the July 14, 1971 event. The inversion was performed several times assuming different depths for the epicenter and different source time histories. The largest error reduction was obtained using an initial source depth of 28 $\mathrm{km}$ and subevent wavelets with a symmetric trapezoidal time history with a rise time of $5 \mathrm{~s}$ and duration of $12 \mathrm{~s}$. The observed and synthetic waveforms and the deconvolved spike train for each station are shown in Fig. 12. The seismograms for this event are much simpler than those from the July 14 event, and the corresponding fits of the synthetics are also superior. The poorest fit is obtained at station SBA. Teleseismic $P$ wave recordings from this station are often difficult to model, which suggests that a complex receiver structure exists beneath SBA or that the instrument is not properly calibrated. The total error reduction after 15 iterations was $72 \%$, although it should be noted that the amplitudes were normalized in this procedure.

The spatial location of the first eight point sources, and the source spike train and moment rate function for a station at a distance of $90^{\circ}$ and azimuth of $330^{\circ}$ from the source are shown in Fig. 13. The results of this inversion are consistent with those obtained from the single station deconvolutions. Most of the body wave moment release in this earthquake occurred close to the epicenter in a westward direction during the first 16-18 $\mathrm{s}$. The exact rupture extent is difficult to ascertain from the simultaneous inversion results. However, if we interpret the termination of the largest subevent $\sim 21 \mathrm{~km}$ west of the epicenter (Fig. 13) to be equivalent to the truncation event of the single station deconvolutions, we can approximate the rupture extent to be $42 \mathrm{~km}$. This allows for the $7 \mathrm{~s}$ subevent duration and assumes a reasonable unilateral rupture velocity of $3 \mathrm{~km} \mathrm{~s}^{-1}$. This distance is slightly less than the value we determined through the directivity analysis, but considering the difference in technique, it provides a consistent interpretation of the rupture of this event (Fig. 14).

Kikuchi and Fukao (1987) also studied the P waves from this event and found that most of the moment release took place within $60 \mathrm{~km}$ of the epicenter in the first $20 \mathrm{~s}$. Their body wave moment was less than one-half of the long-period surface wave moment. They recovered the missing moment by adding it uniformly to their moment rate function over a source time of $100 \mathrm{~s}$. From surface wave analysis, Lay and Kanamori (1980) determined a southwest rupture length of $200 \mathrm{~km}$ for this event; it is therefore not surprising to recover less than half of this moment in a rupture area of only $60 \mathrm{~km}$. We interpret the area between the epicenter and the spatial location of the truncation of the moment rate function $\sim 60 \mathrm{~km}$ away as an asperity. The rupture of this asperity is primarily responsible for the generation of energy in the body wave frequency band, whereas the longer duration rupture propagation down the trench to the southwest apparently proceeded smoothly, and is primarily responsible for the generation of the long-period surface waves.

\section{Discussion}

Our interpretation of the rupture history of the 1971 Solomon Islands doublet events is shown 

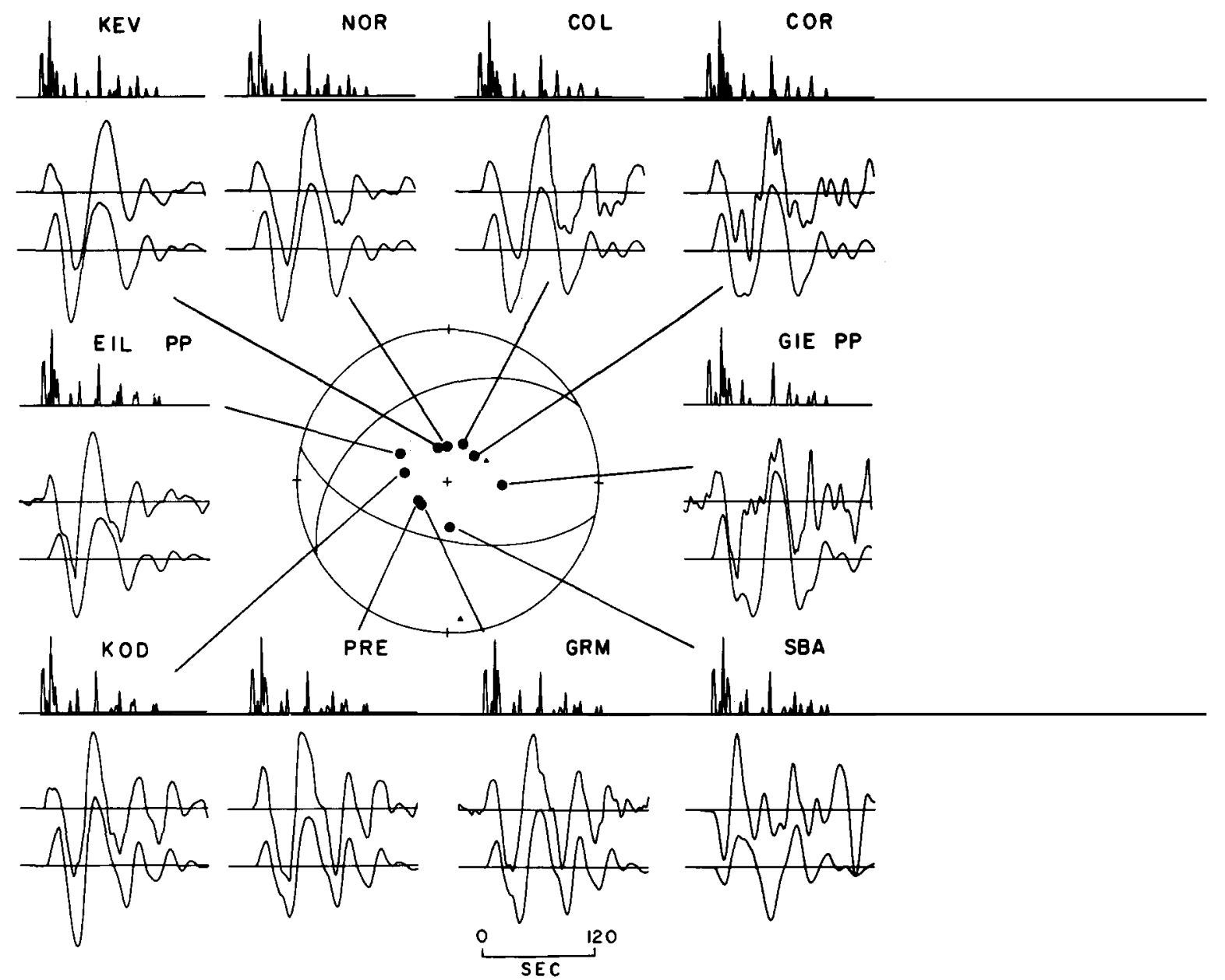

Fig. 12. Observed (top) and synthetic (bottom) seismograms and deconvolved spike trains for the July 26 event resulting from the two-dimensional simultaneous inversion.

schematically in Fig. 15. Rupture of the July 14 event propagated along the strike of the Solomon Islands Trench on a north-ward-curving fault plane associated with a cusp in the subducting Solomon Sea Plate. The body wave moment release was dominated by two subevents, one occurring near the epicenter and the other in the vicinity of the Solomon Islands-New Britain arc-arc junction. The northeasterly slip in the Solomon Island Trench triggered failure of an adjacent asperity, 12 days layer, in the New Britain Trench. The effectiveness of earthquake triggering between these two events suggests that the subducted litho- sphere is not torn across this arc-arc junction. Such an interpretation is plausible, as no conspicuous gaps in seismicity are present in the shallow portion of the Wadati-Benioff zone (Cooper and Taylor, 1987). Additional support for continuity of the subducted lithosphere comes from a study by Yamaoka et al. (1986), who were able to match successfully the shape of the Wadati-Benioff zone in the vicinity of the Solomon Islands-New Britain Trench junction through bending alone, without the introduction of lithospheric tear faults. The continuous curvature of the lithosphere around the arc-arc corner 


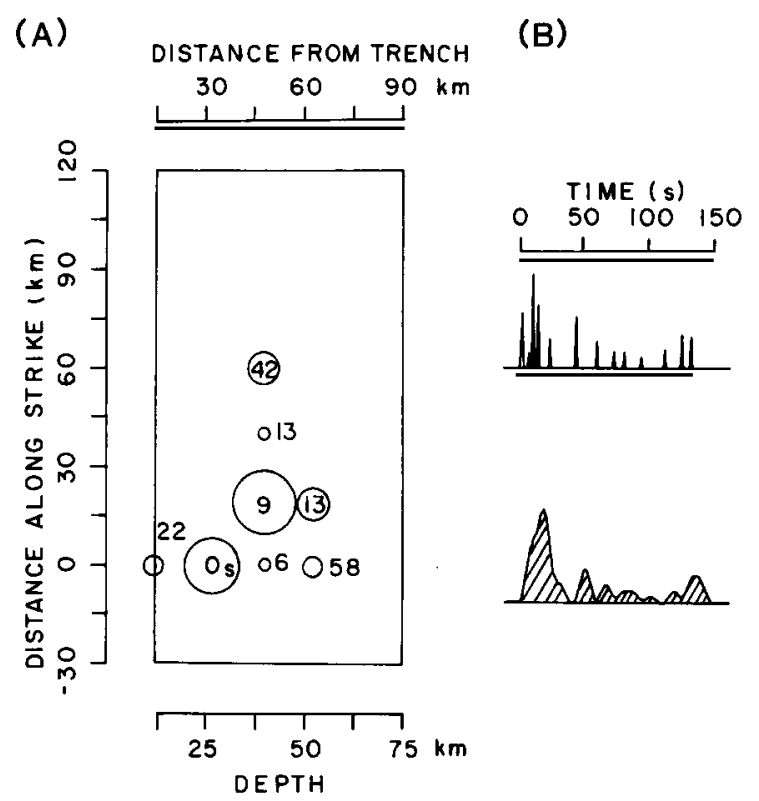

Fig. 13. (A) Spatial distribution of subevents for the July 26 , 1971 event resulting from the two dimensional simultaneous inversion. The radii of the circles are proportional to the seismic moment of the individual subevents. The number inside each circle represents the time of that subevent's initiation. (B) Average source time function and deconvolved spike train obtained from the body wave inversion.

requires a shallowing of the fault plane dip as the corner is approached (Fig. 15). This shallowing of dip angle creates a larger contact surface between the subducting and overriding plates, therefore locally increasing their degree of mechanical coupling. The local increase in coupling in the vicinity of the arc-arc junction, caused by the geometry of subduction, may explain its location as an area of major moment release for both of the 1971 earthquakes (Fig. 15). This increased coupling may also be responsible for generating the largest known earthquake sequences in the Solomon Islands.

An association between asperities and geometric properties of the subducting plate may exist for other subduction zone earthquakes as well. Like the 1971 Solomon Islands doublet events, the 1968 Tokachi-Oki earthquake occurred at the junction of two arcs (Kurile Islands and Japan Arcs). Mori and Shimazaki (1984), Schwartz and Ruff (1985), and Kikuchi and Fukao (1985) all identified a

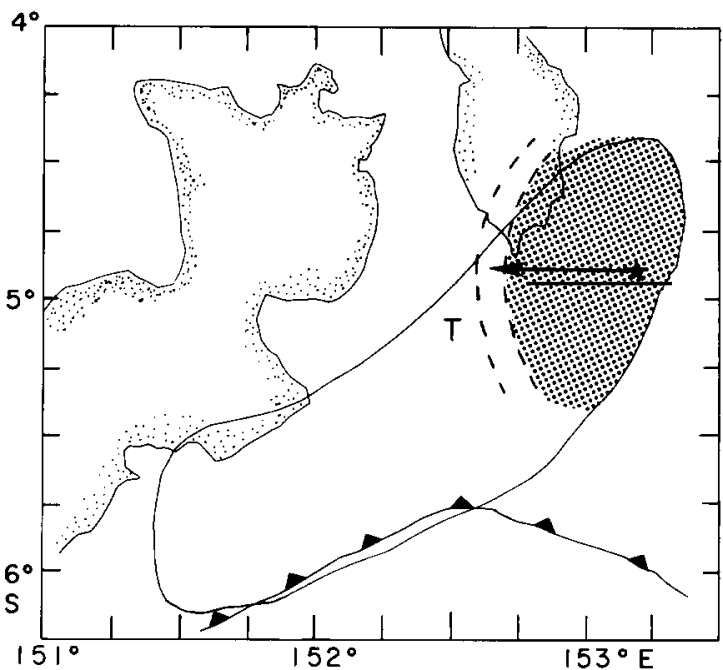

Fig. 14. Map location of the positions corresponding to the event $T$ observed on the single station source time functions for the July 26 event. The unmarked dashed line is the approximate rupture extent of the largest subevent determined by the multi-station deconvolution. The area between the epicenter and the dashed lines (shaded region) is responsible for releasing most of the moment in the body wave frequency band.

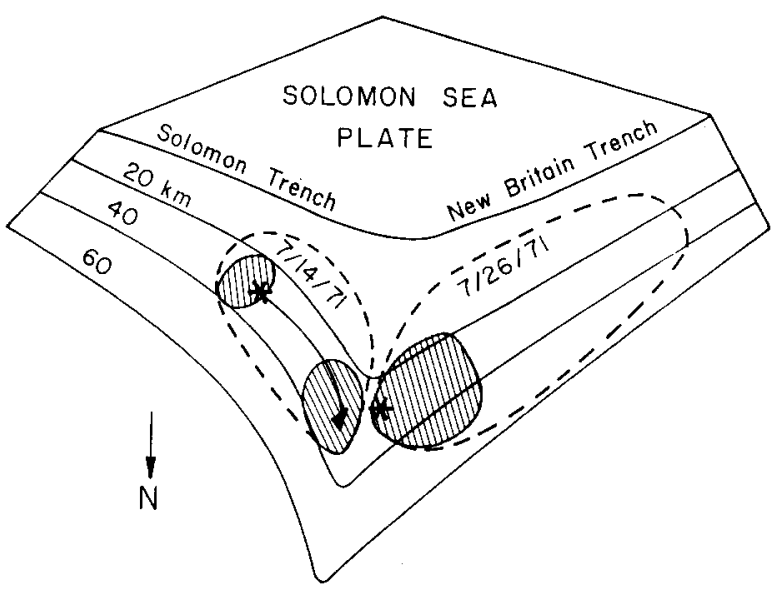

Fig. 15. Schematic interpretation of the rupture history of the 1971 Solomon Islands doublet sequence. Rupture of the July 14 event propagated along strike of the Solomon Islands Trench on a northward curving fault plane. The primary body wave moment was released in two regions, one near the epicenter and the other in the vicinity of the Solomon Islands-New Britain arc-arc junction. The rupture of the July 14 event triggered failure of an adjacent asperity, which ruptured in the large July 26 event. A local increase in mechanical coupling between the subducting and overriding lithosphere, resulting from the subduction geometry, may be responsible for the localization of stress in the region of the arc-arc junction. 
region of large moment release associated with the rupture of the 1968 Tokachi-Oki earthquake that corresponded with a peculiar area of the fault plane. The high moment release subevent is located adjacent to the largest aftershock, which had a normal fault focal mechanism with a sense of displacement opposite to that of the main event (Kanamori, 1971). Kanamori (1971) proposed that this aftershock, and other anomalous earthquakes in the area, result from oblique subduction of the oceanic lithosphere at the arc-arc junction that causes the corner of the subducting plate to buckle and experience displacement in the opposite sense of subduction.

The contortion of the subducting plate may have also produced a local region of enhanced coupling that failed as an asperity in the 1968 Tokachi-Oki mainshock.

\section{Conclusion}

We have presented the first model for the source process of the July 14, 1971 Solomon Islands earthquake that is consistent with both the body wave and surface wave observations. We believe that this earthquake propagated along a continuously curving fault surface, which, for the purpose of modeling, was approximated using two faulting geometries. The body waves reveal distinct episodes of moment release associated with each fault segment, one near the epicenter and the other in the vicinity of the Solomon Islands-New Britain arc-arc junction. The July 26 event had a comparatively simple rupture process, with most of the moment in the body wave frequency band released within $60 \mathrm{~km}$ of the epicenter, whereas the surface wave radiation was produced by smooth rupture over a larger area. The study of these earthquakes has helped to define the geometry of the subducted Solomon Sea Plate at the corner of the Solomon Islands-New Britain Trenches. We found an association between the distribution of stress heterogeneity over the fault surface, as revealed in the spatial distribution of moment release, and the contortion of the subducting lithosphere. For both events, regions of concentrated moment release have been identified near the
Solomon Islands-New Britain arc-arc junction. A local increase in mechanical coupling between the subducting and overriding lithosphere, resulting from the subduction geometry, may be responsible for the localization of stress in this region.

\section{Acknowledgements}

We are very grateful to John Nabelek for helping us in resolution of the faulting geometry for the July 14, 1971 event by applying his waveform inversion technique to the body wave data set. We also wish to thank Chris Young for his invaluable help throughout this project. This research was partially funded by NSF grants EAR-8351515 and EAR-8407786 to L.J.R. S.Y.S. was supported by an AMOCO PhD Graduate Fellowship and T.L. by NSF Grant EAR-8451715.

\section{References}

Cooper, P. and Taylor, B., 1987. Morphology of the Wadati-Benioff zone at the New Britain corner. Trans. Am. Geophys. Union, EOS, 44: 1445.

Johnson, T. and Molnar, P., 1972. Focal mechanisms and plate tectonics of the southwest Pacific. J. Geophys. Res., 77: $5000-5032$.

Kanamori, H., 1970. Synthesis of long-period surface waves and its application to earthquake source studies-Kurile Islands earthquake of October 13, 1963. J. Geophys. Res., 75: 5011-5027.

Kanamori, H., 1971. Focal mechanism of the Tokachi-Oki earthquake of May 16, 1968: contortion of the lithosphere at a junction of two trenches. Tectonophysics, 12: 1-13.

Kanamori, H., 1981. The nature of seismicity patterns before major earthquakes. In: D.W. Simpson and P.G. Richards (Editors), Earthquake Prediction, an International Review. Am. Geophys. Union, Washington, DC, pp. 1-19.

Kikuchi, M. and Fukao, Y., 1985. Iterative deconvolution of complex body waves from great earthquakes-Tokachi-Oki earthquake of 1968. Phys. Earth. Planet. Inter., 37: 235-248.

Kikuchi, M. and Fukao, Y., 1987. Inversion of long-period P waves from great earthquakes along subduction zones. Tectonophysics, 144: 231-247.

Kikuchi, M. and Kanamori, H., 1982. Inversion of complex body waves. Bull. Seismol. Soc. Am., 72: 491-506.

Kikuchi, M. and Kanamori, H., 1986. Inversion of complex body waves II. Phys. Earth. Planet. Inter., 43: 205-222.

Lay, T. and Kanamori, H., 1980. Earthquake doublets in the Solomon Islands. Phys. Earth. Planet. Inter., 21: 283-304.

Lay, T., Kanamori, H. and Ruff, L., 1982. The asperity model 
and the nature of large subduction zone earthquakes. Earthquake Prediction Res., 1: 3-71.

Lynnes, C.S. and Ruff, L.J., 1985. Use of the PP phase to study the earthquake source. Geophys. Res. Lett., 12: 514-517.

Mori, J. and Shimazaki, K., 1984. High stress drops of shortperiod subevents from the 1968 Tokachi-Oki earthquake as observed on strong motion records. Bull. Seismol. Soc. Am., 74: 1529-1544.

Nabelek, J.L., 1984. Determination of Earthquake Source Parameters from Inversion of Body Waves, $\mathrm{PhD}$ thesis, Massachusetts Institute of Technology, Cambridge, MA, $336 \mathrm{pp}$.

Pascal, G., 1979. Seismotectonics of the Papua New Guinea-Solomon Islands region. Tectonophysics, 57: 7-34.
Ruff, L. and Kanamori, H., 1983. The rupture process and asperity distribution of three great earthquakes from longperiod diffracted P-waves. Phys. Earth. Planet. Inter., 31: 202-230.

Schwartz, S.Y. and Ruff, L.J., 1985. The 1968 Tokachi-Oki and the 1969 Kurile Islands earthquakes: variability in the rupture process. J. Geophys. Res., 90: 8613-8626.

Yamaoka, K., Fukao, Y. and Kumuzawa, M., 1986. Spherical shell tectonics: effects of sphericity and inextensibility on the geometry of the descending lithosphere. Rev. Geophys., 24: 27-53. 